08,07

\title{
Влияние дефектности углеродной подрешетки на упругие свойства кубического карбида титана $\mathrm{TiC}_{y}$
}

\author{
(C) А.И. Гусев \\ Институт химии твердого тела УрО РАН, \\ Екатеринбург, Россия \\ E-mail: gusev@ihim.uran.ru
}

Поступила в Редакцию 18 июня 2021 г.

В окончательной редакции 18 июня 2021 г.

Принята к публикации 22 июня 2021 г.

\begin{abstract}
Впервые оценены изменения упругих постоянных $c_{i j}$ неупорядоченного кубического карбида титана $\mathrm{TiC}_{y}$ с ростом дефектности углеродной подрешетки. Установлено, что что отклонение карбида титана от стехиометрического состава $\mathrm{TiC}_{1.0}$ приводит к уменьшению констант упругой жесткости $c_{i j}$ неупорядоченного карбида $\mathrm{TiC}_{y}$ при одновременном увеличении упругой анизотропии. Рассчитаны распределения модуля Юнга $E$ и коэффициента Пуассона $\mu$ в плоскости (100) и распределения модуля сдвига $G$ в плоскостях $(100)$, (110) и (111) как функции кристаллографического направления $[h k l]$ и относительного содержания углерода $y$ в карбиде $\mathrm{TiC}_{y}$. Самые низкие значения модуля сдвига $G_{h k l}$ для $\mathrm{TiC}_{y}$ наблюдаются в плоскости (111).
\end{abstract}

Ключевые слова: карбид титана, нестехиометрия, вакансии, упругие свойства.

DOI: $10.21883 /$ FTT.2021.11.51598.151

\section{1. Введение}

Кубический (пр.гр. $F m \overline{3} m)$ карбид титана $\mathrm{TiC}_{y}$ имеет самую широкую область гомогенности от $\sim \mathrm{TiC}_{0.47-0.48}$ до $\mathrm{TiC}_{1.00}$ среди всех сильно нестехиометрических карбидов $[1,2]$. Все свойства карбида титана зависят от относительного содержания углерода у и заметно меняются в его области гомогенности [1,3]. Благодаря сочетанию высокой твердости и малой плотности с высокими термической и коррозионной стойкостью, карбид титана имеет очень большой потенциал для технического применения, включая безвольфрамовые твердые сплавы для металлообработки [3,4], нанокомпозиты [3], твердые покрытия [5], ингибиторы роста зерна [6].

Определение составов $\mathrm{TiC}_{y}$, которые будут обладать пониженной хрупкостью и повышенной пластичностью при сохранении высоких механических свойств, является важной задачей изучения карбида титана. Изменение нестехиометрии карбида титана может быть полезным для достижения этой цели.

Сведения об упругих свойствах карбида титана нужны для предсказания механических свойств различных фаз карбида титана, для определения условий получения нанокристалических порошков $\mathrm{TiC}_{y}$ методами механохимии, включая высокоэнергетический размол.

Систематические измерения упругих свойств неупорядоченного кубического карбида титана $\mathrm{TiC}_{y}$ в зависимости от его состава в литературе отсутствуют, хотя в отдельных работах приведены сведения о величине модуля всестороннего сжатия $B$ и модуля сдвига $G$ карбидов титана $\mathrm{TiC}_{y}$ с разным содержанием углерода $y$ [7-18].

Теоретические оценки упругих свойств, полученные, как правило, в разных вариантах теории функционала плотности с использованием приближений локальной плотности (LDA) и обобщенного градиента (GGA) для обменно-корреляционных потенциалов, имеются только для стехиометрического карбида титана $\mathrm{TiC}_{1.0}$ и представлены в работах [14,19-28]. Результаты теоретического расчета упругих констант $c_{i j}$ стехиометрического $\mathrm{TiC}_{1.0}$ в разных работах отличаются весьма заметно: согласно $[14,24,25] c_{11} \cong 470, c_{12} \cong 105$ и $c_{44} \cong 170 \mathrm{GPa}$, а по данным [20,21] эти же константы упругой жесткости больше и равны 603-610, 103-124 и 173-181 GPa соответственно. Заметим, что использование в расчетах приближения LDA приводит к большим значениям $c_{i j}$ по сравнению с приближением GGA.

В последнее время поиск возможных стабильных сверхструктур в нестехиометрических карбидах проводится с помощью эволюционного алгоритма, реализованного в программе USPEX (Universal Structure Predictor: Evolutionary Xtallography) [29]. Упругие свойства прогнозируемых карбидных сверхструктур оцениваются путем расчета коэффициентов тензора упругости с использованием метода конечных разностей [30], реализованного в программном пакете VASP (Vienna Ab initio Simulation Package) [31,32]. Однако применение указанных программных продуктов позволяет оценить упругие свойства только упорядоченных карбидных фаз (сверхструктур), тогда как упругие свойства неупорядоченных нестехиометрических карбидов остаются неизвестными. Например, в работах $[33,34]$ рассчитаны упругие свойства двух стабильных при $T=0 \mathrm{~K}$ и $P=0 \mathrm{GPa}$ упорядоченных фаз карбида титана: сверхструктуры $\mathrm{Ti}_{2} \mathrm{C}$ с тригональной и кубической симметрией и сверхструктуры $\mathrm{Ti}_{3} \mathrm{C}_{2}$ с моноклинной или орторомбической симметрией. Согласно [34], при высоком давлении > $40 \mathrm{GPa}$ 
в карбиде титана стабильны две тетрагональные фазы $\mathrm{Ti}_{2} \mathrm{C}$ и $\mathrm{Ti}_{3} \mathrm{C}_{2}$.

Настоящая работа посвящена полуэмпирической оценке упругих констант $c_{i j}$ неупорядоченного нестехиометрического карбида титана $\mathrm{TiC}_{y}$ в зависимости от его состава с помощью совместного критического анализа экспериментальных результатов [7-18] по механическим свойствам карбида титана с разным содержанием углерода и теоретических данных по упругим константам стехиометрического карбида $\mathrm{TiC}_{1.0}$. Для нестехиометрических соединений типа кубических карбидов переходных металлов подобный подход к оценке упругих свойств неупорядоченных фаз использован впервые.

\section{2. Результаты и обсуждение}

Зависимость модуля всестороннего сжатия $B$ карбида титана $\mathrm{TiC}_{y}$ от относительного содержания углерода $y$, построенная по экспериментальным данным [7-14], показана на рис. 1. Рост дефектности углеродной подрешетки вследствие снижения содержания углерода у от 1.0 до 0.5 сопровождается небольшим (примерно на $20 \mathrm{GPa}$ ) уменьшением модуля $B$. В соответствии с аппроксимацией экспериментальных значений $B$, модуль всестороннего сжатия стехиометрического карбида $\mathrm{TiC}_{1.0} 0$ равен $B_{y=1}=241.7 \mathrm{GPa}$. Количественно зависимость модуля всестороннего сжатия карбида титана от содержания углерода $B(y)$ при $300 \mathrm{~K}$ можно описать как

$$
\begin{aligned}
& B(y)=183.5+98.8 y-40.6 y^{2} \\
& =B_{y=1}\left(0.75938+0.40879 y-0.16817 y^{2}\right) \pm 10.0 \mathrm{GPa} .
\end{aligned}
$$

Данные [8-10,13,15-18] по модулю сдвига $G$ в зависимости от состава карбида $\mathrm{TiC}_{y}$ показаны на рис. 2 . Отклонение состава карбида титана от стехиометрии

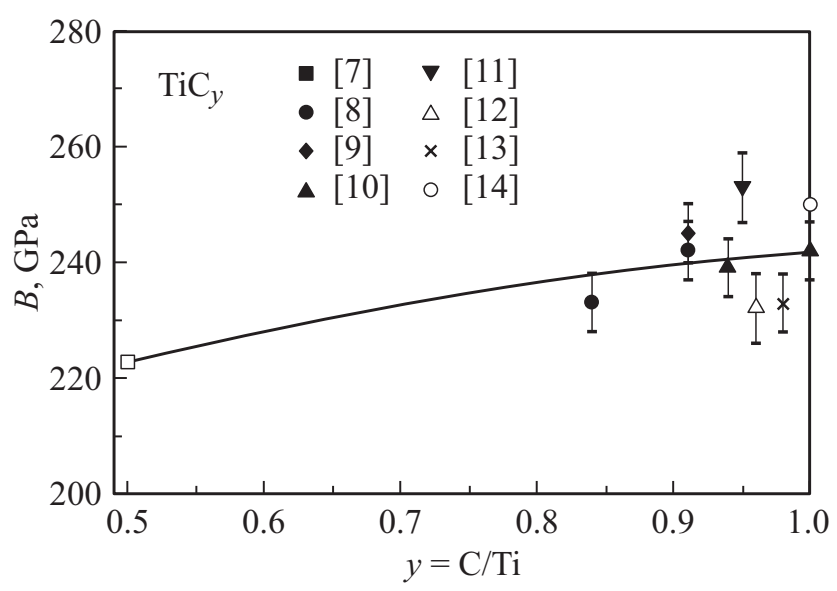

Рис. 1. Изменение модуля всестороннего сжатия $B$ в области гомогенности неупорядоченного кубического карбида титана $\mathrm{TiC}_{y}$ при $300 \mathrm{~K}: \mathbf{-}-[7], \bullet-[8], \diamond-[9], \boldsymbol{\Delta}-[10], \boldsymbol{\nabla}-[11]$, $\triangle-[12], \times-[13]$, o- [14]. Аппроксимирующая зависимость $B(y)$ показана сплошной линией.

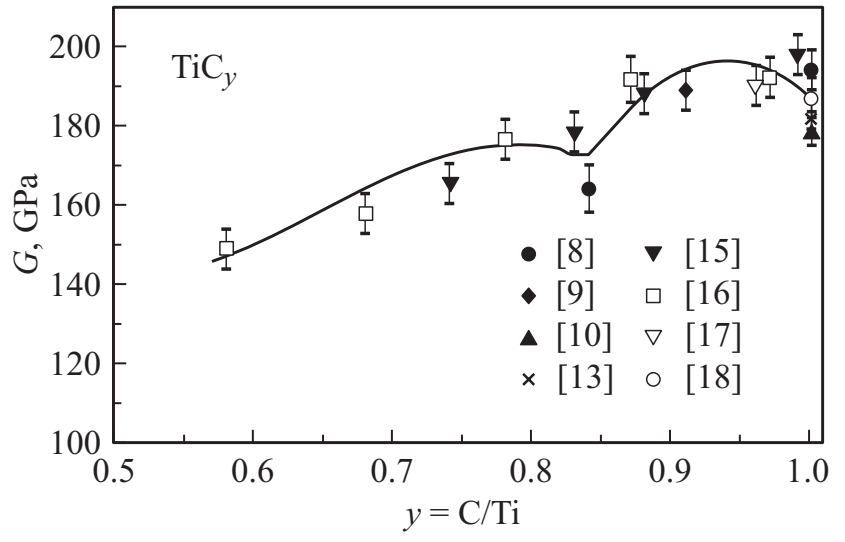

Рис. 2. Зависимость модуля сдвига $G$ от состава неупорядоченного кубического карбида титана $\mathrm{TiC}_{y}$ при температуре $300 \mathrm{~K}: \bullet-[8], \diamond-[9], \mathbf{\Delta}-[10], \times-[13], \mathbf{\nabla}-[15], \square-$ $[16], \triangle-[17]$, o $-[18]$. Аппроксимирующая зависимость $G(y)$ показана сплошной линией.

приводит к нелинейному изменению $G$ : модуль сдвига увеличивается при переходе от $\mathrm{TiC}_{1.0}$ к $\sim \mathrm{TiC}_{0.92}$, затем уменьшается до явно выраженного минимума в области $\mathrm{TiC}_{0.87}-\mathrm{TiC}_{0.81}$. При уменьшении $y$ до $\sim 0.78$ модуль $G$ слабо увеличивается, а затем монотонно снижается при дальнейшем уменьшении $y$ до $\sim 0.55$. Согласно выполненному аппроксимационному расчету, модуль сдвига стехиометрического карбида $\mathrm{TiC}_{1.00}$ coставляет $G_{y=1}=187.2 \mathrm{GPa}$. С учетом этого и наблюдаемого минимума $G$ зависимость модуля сдвига $G(y)$ от содержания углерода $y$ в карбиде $\mathrm{TiC}_{y}$ при $300 \mathrm{~K}$ можно представить функцией

$$
\begin{aligned}
& G(y)=G_{y=1}\left[\left(-11.03975+25.74769 y-13.70794 y^{2}\right)\right. \\
& \times f_{H}\left(y-y_{b}\right)+\left(-0.82182+4.41716 y-2.76328 y^{2}\right) \\
& \left.\times f_{H}\left(y-y_{b}\right)\right] \pm 10.0 \mathrm{GPa}
\end{aligned}
$$

где

$$
f_{\mathrm{H}}\left(y-y_{b}\right)= \begin{cases}1, & \text { if } \quad y \geq y_{b} \\ 0, & \text { if } y<y_{b}\end{cases}
$$

— функция Хевисайда с $y_{b}=0.84$.

Модули всестороннего сжатия и сдвига изотропных кубических кристаллов связаны с константами упругой жесткости следующими соотношениями: $B=$ $=\left(c_{11}+2 c_{12}\right) / 3$ и $G=c_{44}[35]$. В первом приближении можно предположить, что зависимости $B(y)$ и $G(y)$ монокристаллического карбида титана $\mathrm{TiC}_{y}$ от относительного содержания углерода $y$ имеют такой же вид, как количественные зависимости $B(y)(1)$ и $G(y)(2)$, найденные на основе экспериментальных данных [7-18]. Иначе говоря,

$$
\left(c_{11}+2 c_{12}\right) / 3 \sim B_{y=1}\left(0.75938+0.40879 y-0.16817 y^{2}\right)
$$


Константы упругой жесткости $c_{i j}(\mathrm{GPa})$, константы упругой податливости $s_{i j}\left(\mathrm{~Pa}^{-1}\right)$ и критерий упругой анизотропии $A_{\text {an }}$ для карбида титана $\mathrm{TiC}_{y}$ с разным содержанием углерода $y$

\begin{tabular}{c|c|c|c|c|c|c|c}
\hline$y$ & $c_{11}$ & $c_{12}$ & $c_{44}$ & $s_{11}$ & $s_{12}$ & $s_{44}$ & $A_{\text {an }}$ \\
\hline 0.50 & 478.4 & 106.0 & 127.4 & $2.273 \cdot 10^{-12}$ & $-0.412 \cdot 10^{-12}$ & $7.852 \cdot 10^{-12}$ & 0.684 \\
0.55 & 484.4 & 107.3 & 141.2 & $2.245 \cdot 10^{-12}$ & $-0.407 \cdot 10^{-12}$ & $7.081 \cdot 10^{-12}$ & 0.749 \\
0.60 & 490.0 & 108.6 & 152.6 & $2.219 \cdot 10^{-12}$ & $-0.403 \cdot 10^{-12}$ & $6.555 \cdot 10^{-12}$ & 0.800 \\
0.65 & 495.1 & 109.7 & 161.4 & $2.196 \cdot 10^{-12}$ & $-0.398 \cdot 10^{-12}$ & $6.197 \cdot 10^{-12}$ & 0.837 \\
0.70 & 499.9 & 110.8 & 167.7 & $2.175 \cdot 10^{-12}$ & $-0.395 \cdot 10^{-12}$ & $5.964 \cdot 10^{-12}$ & 0.862 \\
0.75 & 504.1 & 111.7 & 171.4 & $2.157 \cdot 10^{-12}$ & $-0.391 \cdot 10^{-12}$ & $5.834 \cdot 10^{-12}$ & 0.874 \\
0.80 & 508.0 & 112.6 & 172.6 & $2.141 \cdot 10^{-12}$ & $-0.388 \cdot 10^{-12}$ & $5.792 \cdot 10^{-12}$ & 0.873 \\
0.85 & 511.4 & 113.3 & 172.3 & $2.126 \cdot 10^{-12}$ & $-0.386 \cdot 10^{-12}$ & $5.802 \cdot 10^{-12}$ & 0.866 \\
0.90 & 514.4 & 114.0 & 188.4 & $2.114 \cdot 10^{-12}$ & $-0.383 \cdot 10^{-12}$ & $5.307 \cdot 10^{-12}$ & 0.941 \\
0.95 & 516.9 & 114.5 & 192.0 & $2.104 \cdot 10^{-12}$ & $-0.382 \cdot 10^{-12}$ & $5.209 \cdot 10^{-12}$ & 0.954 \\
1.00 & 519.0 & 115.0 & 183.0 & $2.095 \cdot 10^{-12}$ & $-0.380 \cdot 10^{-12}$ & $5.465 \cdot 10^{-12}$ & 0.906
\end{tabular}

и

$$
\begin{aligned}
c_{44} & \sim G_{y=1}\left[\left(-11.03975+25.74769 y-13.70794 y^{2}\right)\right. \\
& \times f_{\mathrm{H}}\left(y-y_{b}\right)+\left(-0.82182+4.41716 y-2.76328 y^{2}\right) \\
& \left.\times f_{\mathrm{H}}\left(y-y_{b}\right)\right] .
\end{aligned}
$$

Согласно [36], зависимости упругих констант $c_{11}(y)$ и $c_{12}(y)$ от состава кубических карбидов одинаковы. К экспериментальным величинам модулей $B_{y=1}=241.7$ и $G_{y=1}=187.2 \mathrm{GPa}$ наиболее близки теоретические значения модулей $B_{\text {calc, } y=1}=249$ и $G_{\text {calc, } y=1}=190 \mathrm{GPa}$ стехиометрического карбида титана, рассчитанные в GGA приближении в работе [22], а также $B_{\text {calc, } y=1}=250 \mathrm{GPa}$. С учетом этого и сделанного приближения зависимости упругих констант $c_{i j}(y)$ от состава карбида $\mathrm{TiC}_{y}$ можно записать как

$$
\begin{gathered}
c_{11}(y)=c_{11}(y=1)\left[0.75938+0.40879 y-0.16817 y^{2}\right], \\
c_{12}(y)=c_{12}(y=1)\left[0.75938+0.40879 y-0.16817 y^{2}\right], \\
c_{44}(y)=c_{44}(y=1)[(-11.03975+25.74769 y \\
\left.-13.70794 y^{2}\right) f_{\mathrm{H}}\left(y-y_{b}\right)+(-0.82182+4.41716 y \\
\left.\left.-2.76328 y^{2}\right) f_{\mathrm{H}}\left(y-y_{b}\right)\right], \\
f_{\mathrm{H}}\left(y-y_{b}\right)= \begin{cases}1, & \text { if } y \geq y_{b} \\
0, & \text { if } y<y_{b}\end{cases}
\end{gathered}
$$

- функция Хевисайда с $y_{b}=0.84 ; c_{11}(y=1)=519 \mathrm{GPa}$, $c_{12}(y=1)=115 \mathrm{GPa}$ и $c_{44}(y=1)=183 \mathrm{GPa}[22]$.

Постоянные упругой жесткости $c_{11}, c_{12}, c_{44}$ и постоянные упругой податливости $s_{11}, s_{12}, s_{44}$ для кубических кристаллов связаны известными соотношениями: $s_{44}=1 / c_{44}, s_{11}=\left(c_{11}+c_{12}\right) /\left[\left(c_{11}-c_{12}\right)\left(c_{11}+2 c_{12}\right)\right]$ и $s_{12}=-c_{12} /\left[\left(c_{11}-c_{12}\right)\left(c_{11}+2 c_{12}\right)\right][35]$.

Оцененные постоянные упругой жесткости $c_{i j}$ и компоненты $s_{i j}$ тензора податливости карбида титана $\mathrm{TiC}_{y}$ приведены в таблице.
Модуль Юнга $E_{h k l}$ и коэффициент Пуассона $\mu_{h k l}$ кубических кристаллов анизотропны и зависят от кристаллографического направления $[h k l]$. Эти упругие характеристики определяются через компоненты тензора податливости $s_{11}, s_{12}$ и $s_{44}[37]$ как

$$
\begin{gathered}
E_{h k l}=\frac{1}{s_{11}-2\left(s_{11}-s_{12}-\frac{1}{2} s_{44}\right) \Gamma}, \\
\mu_{h k l}=-\frac{s_{12}+\left(s_{11}-s_{12}-\frac{1}{2} s_{44}\right) \Gamma}{s_{11}-2\left(s_{11}-s_{12}-\frac{1}{2} s_{44}\right) \Gamma},
\end{gathered}
$$

где

$$
\Gamma=\frac{h^{2} k^{2}+h^{2} l^{2}+k^{2} l^{2}}{\left(h^{2}+k^{2}+l^{2}\right)^{2}}
$$

- фактор анизотропии кубических кристаллов.

С учетом (4) и (5) модуль сдвиг $G_{h k l}$ и модуль всестороннего сжатия $B$ равны

$$
\begin{gathered}
G_{h k l}=\frac{1}{2 s_{11}-2 s_{12}-6\left(s_{112}-s_{12}-s_{44} / 2\right) \Gamma}, \\
B=1 /\left[3\left(s_{11}+2 s_{12}\right)\right] .
\end{gathered}
$$

Из (7) видно, что модуль всестороннего сжатия $B$ кубических кристаллов не зависит от направления $[h k l]$ и изотропен.

Наличие данных по упругим константам $c_{11}, c_{12}, c_{44}$ и $s_{11}, s_{12}, s_{44}$ карбида $\mathrm{TiC}_{y}$ с разной степенью дефектности углеродной подрешетки (см. таблицу) позволило найти распределения упругих характеристик монокристаллического кубического карбида $\mathrm{TiC}_{y}$ как функции направления $[h k l]$ и относительного содержания углерода $y$. На рис. 3 показаны рассчитанные распределения модуля Юнга $E$, модуля сдвига $G$ и коэффициента Пуассона $\mu$ кубического карбида $\mathrm{TiC}_{y}$. Распределения модуля Юнга $E_{h k l}$ показаны в плоскости (100) для карбидов $\mathrm{TiC}_{y}$ с $y=0.5,0.6,0.7,0.8$ и 1.0 (см. рис. 3). Распределения модуля Юнга $E_{h k l}$ в плоскостях (010) и (001) имеют такой же вид. Модуль Юнга $E_{h k 0}$ карбида $\mathrm{TiC}_{1.0}$ в плоскости $(100)$ изменяется от $\sim 449.7$ 

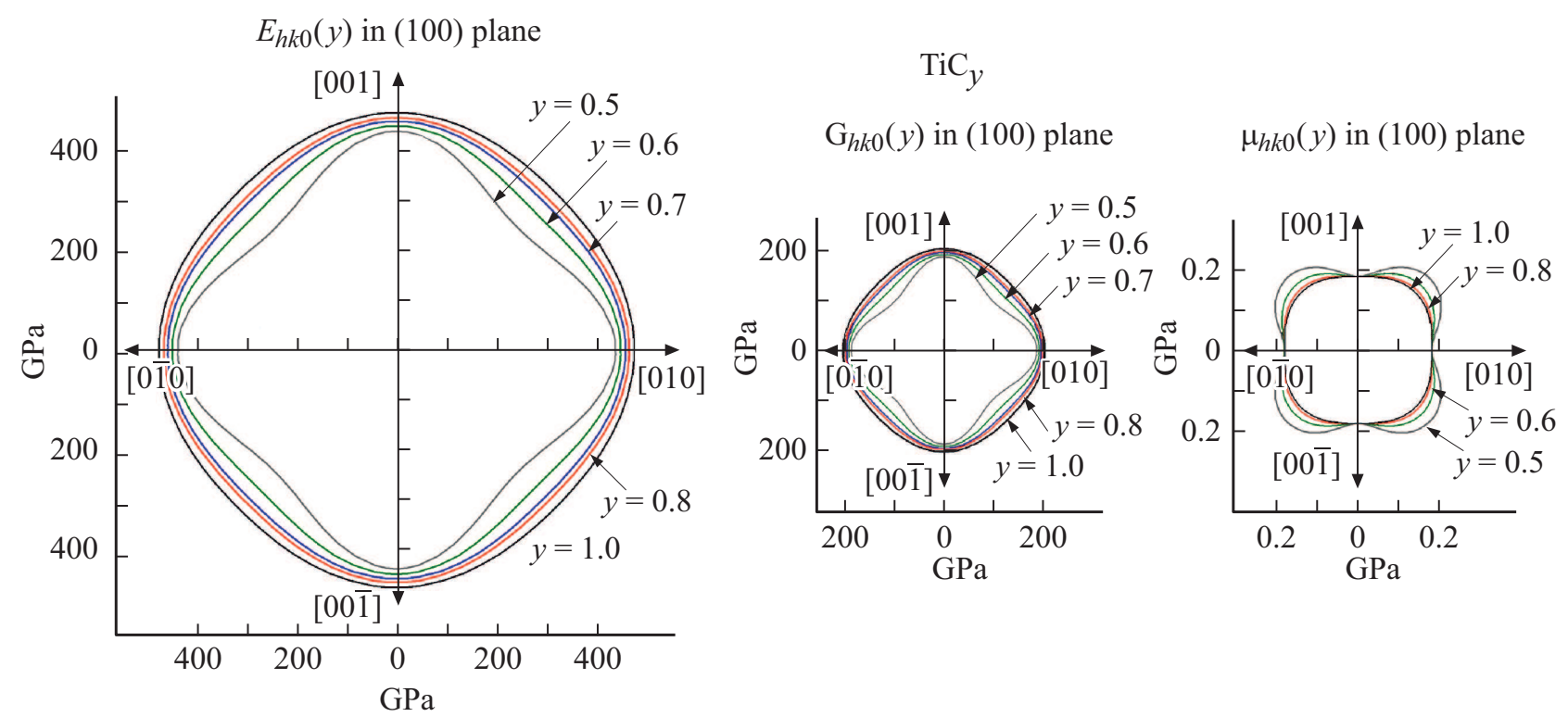

Рис. 3. Зависимости модуля Юнга $E$, модуля сдвига $G$ и коэффициента Пуассона $\mu$ от кристаллографического направления $[h k l]$ в плоскости (100) кубического карбида $\mathrm{TiC}_{y}$ с разным относительным содержанием углерода у от 0.5 до 1.0.
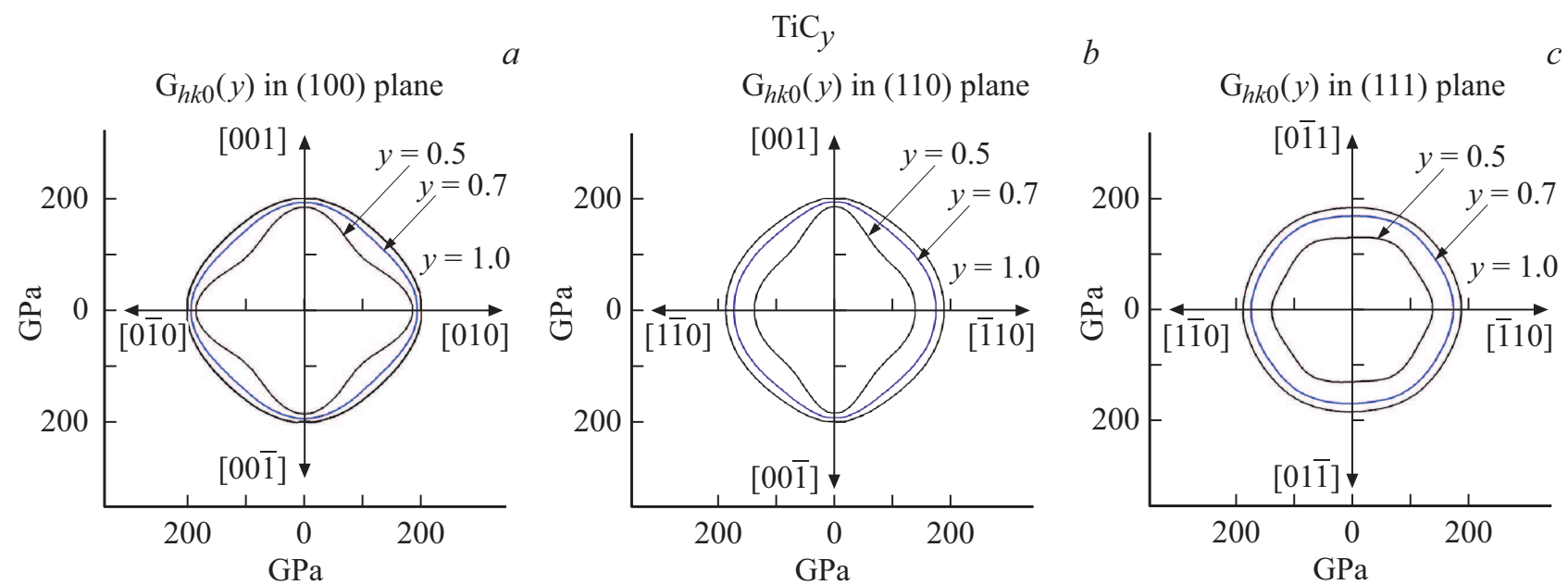

Рис. 4. Распределения модуля сдвига $G_{h k l}$ в зависимости от кристаллографического направления $[h k l]$ в плоскостях $(a)(100)$, (b) (110) и (c) (111) кубического карбида $\mathrm{TiC}_{y}$ с разным содержанием углерода $y$.

до $\sim 477.3 \mathrm{GPa}$, а модуль Юнга нестехиометрического карбида $\mathrm{TiC}_{0.5}$ с дефектной углеродной подрешеткой, содержащей 50\% вакансий, в той же плоскости меняется от $\sim 345.7$ до $\sim 439.9 \mathrm{GPa}$. Максимальная величина модуля сдвига $G_{h k 0}$ немного увеличивается от $\sim 186.2$ до $\sim 202.0 \mathrm{GPa}$ при переходе от нестехиометрического карбида $\mathrm{TiC}_{0.5} \mid$ к стехиометрическому $\mathrm{TiC}_{1.0}$. Увеличение дефектности углеродной подрешетки карбида титана приводит к росту коэффициента Пуассона $\mu$ : в плоскости (100) максимальная величина $\mu$ стехиометрического карбида $\mathrm{TiC}_{1.0}$ составляет $\sim 0.200$, а для нестехиометрического карбида $\mathrm{TiC}_{0.5} \mu_{\max } \cong 0.250$ (см. рис. 3 ). Модуль всестороннего сжатия $B$ кубического карбида титана $\mathrm{TiC}_{y}$ изотропен и зависит только от содержания углерода $y$ : величина $B$ меняется от $\sim 230.1 \mathrm{GPa}$ для $\mathrm{TiC}_{0.5}$ до $\sim 249.7 \mathrm{GPa}$ для стехиометрического $\mathrm{TiC}_{1.0}$.

На рис. 4 показаны рассчитанные зависимости модуля сдвига $G_{h k l}$ карбида $\mathrm{TiC}_{y}$ от кристаллографического направления $[h k l]$. Распределения модуля сдвига $G$ показаны в плоскостях (100), (110) и (111) для карбидов $\mathrm{TiC}_{y}$ с $y=0.5,0.7$ и 1.0. Наименьшая величина $G_{h k l}$ для карбидов $\mathrm{TiC}_{y}$ наблюдается в плоскости (111). Модуль сдвига $G_{h k l}$ в плоскости (111) почти не зависит от направления и слабо меняется от $\sim 184$ до $\sim 187 \mathrm{GPa}$ для $\mathrm{TiC}_{1.0}$, и от $\sim 130$ до $\sim 138 \mathrm{GPa}$ для $\mathrm{TiC}_{0.5}$ (рис. $4, c$ ).

Для количественной характеристики анизотропии упругих свойств кубических кристаллов в работе [38] предложен простой критерий $A_{\text {an }}=2 c_{44} /\left(c_{11}-c_{12}\right)$, величина которого для изотропных кубических кристал- 
лов равна 1. Согласно [38], чем больше величина $A_{\text {an }}$ отличается от 1 , тем больше анизотропия упругих свойств. Рассчитанные значения $A_{\text {an }}$ (см. таблицу) показывают, что отклонение состава карбида титана от близкого к стехиометрии $\mathrm{TiC}_{1.0-0.95}$ до карбида титана $\mathrm{TiC}_{0.50}$ с наибольшей дефектностью углеродной подрешетки сопровождается уменьшением $A_{\text {an }}$ от $\sim 0.91-0.95$ до $\sim 0.68$, т.е. приводит к увеличению анизотропии упругих свойств неупорядоченного карбида титана с ростом дефектности его углеродной подрешетки.

Используя полученные данные по упругим константам $c_{i j}$ и $s_{i j}$ неупорядоченного кубического карбида титана $\mathrm{TiC}_{y}$ с разным относительным содержанием углерода $y$, можно найти температуры Дебая и решеточные (фононные) теплоемкости карбида $\mathrm{TiC}_{y}$ разного состава.

В соответствии с методом усреднения Фойхта-РойссаХилла [39] модули всестороннего сжатия $B$ и модули сдвига $G$ связаны с упругими константами следующими соотношениями

$$
\begin{gathered}
B_{\mathrm{V}}=\left[c_{11}+c_{22}+c_{33}+2\left(c_{12}+c_{13}+c_{23}\right)\right] / 9, \\
B_{\mathrm{R}}=1 /\left[s_{11}+s_{22}+s_{33}+2\left(s_{12}+s_{13}+s_{23}\right)\right], \\
G_{\mathrm{V}}=\left[c_{11}+c_{22}+c_{33}+3\left(c_{44}+c_{55}+c_{66}\right)\right. \\
\left.-\left(c_{12}+c_{13}+c_{23}\right)\right] / 15, \\
G_{\mathrm{R}}=15 /\left[4\left(s_{11}+s_{22}+s_{33}\right)-4\left(s_{12}+s_{13}+s_{23}\right)\right. \\
\left.+3\left(s_{44}+s_{55}+s_{66}\right)\right],
\end{gathered}
$$

а средние величины изотропных модулей определяются как

$$
B=\left(B_{\mathrm{V}}+B_{\mathrm{R}}\right) / 2, \quad G=\left(G_{\mathrm{V}}+G_{\mathrm{R}}\right) / 2 .
$$

Используя изотропные модули $B$ и $G$ карбида $\mathrm{TiC}_{y}$, при известной плотности $\rho$ можно рассчитать продольную $v_{L}$, поперечную $v_{t}$ и среднюю $v_{m}$ скорости распространения упругих колебаний (скорости распространения звука) [40,41]:

$$
\begin{gathered}
v_{\mathrm{L}}=\sqrt{(3 B+4 G) / 3 \rho}, v_{t}=\sqrt{G / \rho}, \\
v_{m}=\left[\frac{1}{3}\left(\frac{2}{v_{t}^{3}}+\frac{1}{v_{\mathrm{L}}^{3}}\right)\right]^{-1 / 3} .
\end{gathered}
$$

Температуру Дебая можно оценить по средней $v_{m}$ скорости распространения упругих колебаний [41]:

$$
\theta_{\mathrm{D}}=\frac{h}{k_{\mathrm{B}}}\left(\frac{3 n N_{A} \rho}{4 \pi M}\right)^{1 / 3} v_{m}[\mathrm{~K}] .
$$

Далее по найденной величине температуры Дебая можно рассчитать теплоемкость любого карбида $\mathrm{TiC}_{y}$. В пренебрежении вкладом оптических колебаний решеточный дебаевский вклад в теплоемкость карбида $\mathrm{TiC}_{y}$ имеет вид

$$
C_{\mathrm{D}}=(1+y) \frac{12 \pi^{4} k_{\mathrm{B}} N_{A}}{5}\left(\frac{T}{\theta_{\mathrm{D}}}\right)^{3}
$$

В литературе сведения о теплоемкости $\mathrm{TiC}_{y}$ ограничены ее оценкой в работе [42] на основе результатов нейтронографических измерений. Авторам [42] в продолжение своих исследований было бы полезно оценить теплоемкость $\mathrm{TiC}_{y}$, используя представленные данные по упругим константам.

\section{3. Заключение}

В целом в работе впервые определены упругие константы $c_{i j}$ и $s_{i j}$ как функции содержания углерода $y$ в области гомогенности $\mathrm{TiC}_{0.5}-\mathrm{TiC}_{1.0}$ нестехиометрического неупорядоченного кубического карбида титана $\mathrm{TiC}_{y}$. Выполненный анализ показал, что константы упругой жесткости $c_{i j}$ неупорядоченного карбида $\mathrm{TiC}_{y}$ уменьшаются с ростом дефектности углеродной подрешетки карбида титана. Увеличение дефектности углеродной подрешетки карбида $\mathrm{TiC}_{y}$ сопровождается ростом анизотропии упругих свойств.

\section{Финансирование работы}

Работа выполнена по государственному заданию № 0397-2019-0001 в Институте химии твердого тела Уральского отделения Российской Академии наук.

\section{Конфликт интересов}

Автор заявляет об отсутствии конфликта интересов.

\section{Список литературы}

[1] A.I. Gusev, A.A. Rempel, A.J. Magerl. Disorder and Order in Strongly Nonstoichiometric Compounds. Transition Metal Carbides, Nitrides and Oxides. Springer-Verlag, BerlinHeidelberg-N.Y. (2001). 608 p.

[2] J.L. Murray. In: Binary Alloy Phase Diagrams / Ed. T.B. Massalski. Metals Park (Ohio, USA): ASM Intern. Publ. (1987). V. 1. P. 593-596.

[3] В.Н. Липатников, А.И. Гусев. Упорядочение в карбидах титана и ванадия. УрО РАН, Екатеринбург (2000). 265 с.

[4] S.Y. Zhang. Mater. Sci. Eng. A 163, 1, 141 (1993).

[5] J. Musil. Surf. Coat. Technol. 125, 1-3, 322 (2000).

[6] C.W. Morton, D.J. Wills, K. Stjernberg. Int. J. Refr. Met. Hard Mater. 23, 4-6, 287 (2005).

[7] A.P. Miodownik. Mater. Sci. Technol. 10, 3, 190 (1994).

[8] R.H.J. Hannink, M.J. Murray. J. Mater. Sci. 9, |it2, 223 (1974).

[9] R. Chang, L.J. Graham. J. App. Phys. 37, 10, 3778 (1966).

[10] J.J. Gilman, B.W. Roberts. J. Appl. Phys. 32, 7, 1405 (1961).

[11] L. Pintschovius, W. Reichardt, B. Scheerer. J. Phys. C 11, 8 , 1557 (1978).

[12] И.Н. Францевич, Е.А. Жураковский, А.Б. Лященко. Изв. АН СССР. Неорган. материалы 3, 1, 8 (1967).

[13] S.P. Dodd, M. Cankurtaran, B. James. J. Mater. Sci. 38, 6, 1107 (2003).

[14] W.-X. Feng, S.-X. Cui, H.-Q. Hu, G.-Q. Zhang. Physica B 406, 19, 3631 (2011). 
[15] В.Г. Букатов. Исследование физико-механических свойств карбидов тугоплавких металлов и некоторых сплавов на их основе / Автореф. канд. дис. МИСиС, М. (1979). 21 с.

[16] Ю.Г. Ткаченко, С.С. Орданьян, В.К. Юлюгин, Д.З. Юрченко, Г.С. Табатадзе, И.Б. Пантелеев. Порошковая металлургия, № 6, 45 (1979).

[17] С.В. Борисов, Б.В. Митрофанов, Г.П. Швейкин. Изв. АН СССР. Неорган. материалы 15, 12, 2142 (1979).

[18] Q. Yang, W. Lengauer, T. Koch, M. Scheerer, I. Smid. J. Alloys Comp. 309, 1-2, L5 (2000).

[19] R. Ahuja, O. Eriksson, J.M. Wills, B. Johansson. Phys. Rev. B 53, 6, 3072 (1996).

[20] W. Wolf, R. Podloucky, T. Antretter, F.D. Fischer. Phil. Mag. B 79, 6, 839 (1999).

[21] A. Zaoui, B. Bouhafs, P. Ruterana. Mater. Chem. Phys. 91, 1, 108 (2005).

[22] Y. Yang, H. Lu, C. Yu, J.M. Chen. J. Alloys Comp. 485, 1-2, 542 (2009).

[23] Y.H. Li, W.F. Wang, B. Zhu, M. Xu, J. Zhu, Y.J. Hao, W.H. Li, X.J. Long. Sci. China: Phys. Mech. Astron. 54, 12, 2196 (2011).

[24] X.-H. Wang, M. Zhang, L. Ruan, Z.-D. Zou. Trans. Nonferrous Met. Soc. China 21, 6, 1373 (2011).

[25] V. Krasnenko, M.G. Brik. Solid State Sci. 14, 10, 1431 (2012).

[26] Y.Z. Liu, Y.H. Jiang, R. Zhou, J. Feng. J. Alloys Comp. 582, 500 (2014).

[27] Sh.-Q. Ma, Y. Liu, J.-W. Ye, B. Wang. Commun. Theor. Phys. 62, 6, 895 (2014).

[28] D.Y. Dang, J.L. Fan, H.R. Gong. J. Appl. Phys. 116, 3, 033509 (2014).

[29] A.R. Oganov, C.W. Glass. J. Chem. Phys. 124, 24, 244704 (2006).

[30] G. Kresse, J. Furthmüller. Comput. Mater. Sci. 6, |it1, 15 (1996).

[31] G. Kresse, J. Furthmüller. Phys. Rev. B 54, 16, 11169 (1996).

[32] G. Kresse, D. Joubert. Phys. Rev. B 59, 3, 1758 (1999).

[33] D.A. Aksyonov, A.G. Lipnitskii, Yu.R. Kolobov. Comp. Mater. Sci. 65, 434 (2012).

[34] C. Jiang, W. Jiang. Phys. Status Solidi 251, 3, 533 (2014).

[35] R.E. Newnham. Properties of Materials. Anisotropy, Symmetry, Structure. Oxford Univ. Press, N.Y. (2005). 378 p.

[36] A.A. Valeeva, A.I. Gusev. Intern. J. Refr. Met. Hard Mater. 95, 105435 (2021).

[37] T. Gnäupel-Herold, P.C. Brand, H.J. Prask. J. Appl. Crystallogr. 31, 6, 929 (1998).

[38] C. Zener. Elasticity and Anelasticity of Metals. University of Chicago, Chicago (1948). 170 p.

[39] R. Hill. Proc. Phys. Soc. A 65, 5, 349 (1952).

[40] E. Schreiber, O.L. Anderson, N. Soga. Elastic Constants and Their Measurements. McGraw-Hill, N.Y. (1973). 196 p.

[41] O.L. Anderson. In: Lattice Dynamics / Physical Acoustics. Principles and Methods. V. III. Part B. Ch. 2 / Ed. W.P. Mason. Acad. Press, N.Y.-London (1965). P. 45.

[42] И. Хидиров, В.В. Гетманский, А.С. Папиев, Ш.А. Махмудов. Междунар. науч. журн. „Альтернативная энергетика и экология (ISJAEE)“№ 01-03 (285-287), 56-66 (2019). DOI: $10.15518 /$ isjaee.2019.01-03.056-066

Редактор Ю.Э. Китаев 